\title{
A Method for Group Decision Making Involving Subjective Perceptions of Experts' Judgement: A Case of Art Student Placement Process
}

\section{Alpagut YAVUZ Ph.D.}

Associate Professor

Department of Business Administration,

Hatay Mustafa Kemal University, Hatay, Turkey

E-mail: vyavuz@mku.edu.tr

Turkey

\section{ABSTRACT}

Evaluation of artistry mostly depends on subjective perceptions of experts. As a decision-making process, it involves imprecision and fuzziness, and it is difficult to justify the process. Most art programs' admission process involves evaluation of the candidates' pencil drawings and selecting students among competing candidates. Using a justifiable process is essential for the administrators of art programs. Fuzzy MultiCriteria Decision Making methods provide convincing results for real-world problems involving imprecise and fuzzy data. In this study, a modified version of the Fuzzy Analytic Hierarchy Process (FAHP) and TOPSIS methods are proposed for the art student placement process. Delphi technique is used for identifying the evaluation criteria and the FAHP method is used in obtaining the importance of criteria. Rankings of the candidate students are determined using the TOPSIS method. The resulting rank order of drawings is evaluated by the committee members for validating the performance of the proposed method.

\section{Keywords: Fuzzy Analytic Hierarchy Process, TOPSIS, Multi-Criteria Decision Making, Evaluation of Drawings, Student placement}

\section{Introduction}

Multiple criteria decision making (MCDM) involving subjectivity and judgment inherently involves fuzziness in most cases. In the literature, various multiple criteria decisionmaking methods are modified to handle fuzziness in both individual and group decision making processes. Among these methods, Saaty's (1980) Analytic Hierarchy Process (AHP) and the technique for order preference by similarity to ideal solution (TOPSIS) by Hwang and Yoon (1981) are the two widely used methods. There are two distinct ways for the adaptation of fuzzy theory to these methods in the literature. In some studies, (e.g. Chang and Yeh, 2002) methods applied using the crisp values by defuzzifying the fuzzy ratings and weights. However, this approach is criticized on the point that the defuzzification will lose some information. In an attempt to overcome this criticism, in the studies such as Chen (2000), Liang (1999), and Csutora \& Buckley (2001), AHP and TOPSIS methods are generalized in a fuzzy environment without the use of defuzzification.

Using a combination of these two MCDM methods is another strategy adopted to analyze various decision problems. Recently, some studies use a combination of the two MCDM methods. Two methods are employed in fuzzy group decision problems such as performance evaluation of banks (Seçme, Bayrakdaroğlu, and Kahraman, 2009), performance evaluation of transportation firms (Gumus, 2009), performance evaluation of computer manufacturing companies (Sun, 2010), evaluation of robotic systems (Kahraman, Çevik, Ates, and Gülbay, 2007), selection of alliance partner (Büyüközkan, Feyzioğlu, and Nebol, 2007), supplier selection (Wang, Cheng, and Huang, 2009) and selection of customer-oriented product design (Lin, Wang, Chen, and Chang, 2008). In these models, weights for several criteria are determined by Fuzzy AHP (FAHP) and these weights are used for the inputs of the TOPSIS technique to rank the alternatives.

While MCDM methods have been used to understand and analyze these types of group decision making, they have not been used in the evaluation processes of artwork where fuzziness and multiple decision-makers are involved. Thus, this study attempts to explore the applicability of FAHP and TOPSIS methods to a decision making problem in an art case, where there is a certain level of perceptive subjectivity in decision-makers' judgments. The case is the selection of students, for an undergraduate art education program, a process based on the evaluations of candidate students' drawings performed in exams consisting of drawing sessions. This research constructs an iterative and justifiable decisionmaking process out of an abstract and hard to capture evaluation process. For this purpose, a modified version of Fuzzy hierarchical TOPSIS (Wang, Cheng, and Huang, 2009) 
is suggested to analyze a group of experts' subjective/perceptive judgment for evaluating artworks and selecting candidate students for undergraduate art programs.

The rest of the paper is organized as follows. In the next section, the nature of art-related judgment and its role in the art student selection problem is explained. The following section discusses the criteria determination stage for the art student selection exam. Then, a brief preliminary for the fuzzy numbers and fuzzy scales are introduced. The following section introduces the proposed MCDM method for the problem. In the next section, an application for the student selection process is explained. The final section involves a comparison of the results and discussions about the model.

\subsection{Art Student Selection Process}

Art and artistry related decision making involve subjectivity and fuzziness. As in the popular saying "beauty is in the eye of the beholder," art and artistry related judgment may differ to a great extent from one decision-maker to another since it is mostly based on cultural values, education, and personal experiences of the decision-maker. As Volker (2011:15) indicates, judgment is about perception and evaluation; which are two common subjects of psychology. Human perception is the result of an interaction between the physical environment and the person. External and internal factors may cause differences in the outcome of this interaction. In this sense, art assessment is subjective and there is not one universal assessment scheme that can be used in art education. Leder, Belke, Oeberst, and Augustin (2004) have comprehensively modeled the aesthetic experience realized in a person's interaction with a work of art. As Hekkert (2006: 159) puts it, in this model "an observer of an artwork starts with a perceptual analysis of the work, compares this to previous encounters, classifies the work into a meaningful category, and subsequently interprets and evaluates the work, resulting in an aesthetic judgment and an aesthetic emotion". Drawing from Bernstein's (2000) theory of knowledge, Bolton (2006: 60) defines art and art thought in school as "weak knowledge structures made up of series of non-comparable paradigms or languages or approaches." Even though this creates complexity and subjectivity, he argues that there are common criteria for artistic judgments that can be gained through art education. Nodine, Locher, and Krupinski (1993) studied the relationship between the perception of art and training. According to their empirical study, there is a significant difference in the judgments of composition between viewers that are trained or not trained in art.

Receiving an undergraduate level of art education in Turkey requires a student candidate to pass art exams organized by individual universities. Usually, there are two stages of these exams. The first exam is for the elimination, and the second is for the selection of students to be placed in programs. In the elimination exam, candidates are asked to do a pencil drawing from a live model. This exam measures the skills of perception and the application of the perceived onto paper, technical competence, and the ability to master a basic art tool. Candidates who are determined by a group of the jury as unsuccessful are eliminated. The ones who achieve a grade equal or higher to a passing grade, are allowed to enter the second exam. The selection exam usually relies on a hypothetical situation, given to student candidates in short few sentences. For example, the imaginary situation-the exam question - could be a short citation from a literary book or a poem. In any case, student candidates are measured for their ability to visually express the situation described in words originally and creatively. This stage aims to strip the drawing skill from a mere technical (and learned) ability and to reveal the imaginative and expressive skills of the candidate. After this stage, students are placed in undergraduate departments depending on their pre-determined list of choice and cumulative grades from the exams. These two exam stages help the jury in the assessment of candidates' drawings from different fundamental perspectives.

In the art evaluation literature, fundamental elements of evaluation are defined in three general categories: originality, technical competence, and conceptual content (Bolton,2006). Originality reflects the creativity or imagination of the artist. Technical competence involves the artist's mastery to manipulate the art materials and the elements of art. Conceptual content represents how the artist conveys his/her ideas and feelings. In this study, an evaluation committee's (jury) judgment of these elements and the criteria they use are investigated to understand the decision-making process and to explore the applicability of a suitable MCDM model. In solving the decision making problem, the Fuzzy Analytic Hierarchy Process (FAHP) and TOPSIS methods are employed.

\subsection{Criteria for Evaluation of Artwork}

Since the evaluation of art is subjective/perceptive and involves individual judgment shaped by the individual's past experiences and art education, the determination of evaluation criteria needs to be an integral part of the proposed method. This stage requires a group of experts' involvement. And creating consensus among experts on the evaluation criteria is an important task. For this purpose, The Delphi method introduced by Linstone and Turoff (1975) stands out as the best-known method for controlled, anonymous group interaction (Kleindorfer, Kunreuther, and Schoemaker, 1993: 235). The Delphi method consists of five procedures:

(1) expert panel selection; (2) first stage questionnaire distribution; (3) statistical analysis of first stage responses; (4) second stage questionnaire distribution together with first stage results and supporting information from experts; (5) statistical analysis of second stage responses; (6) integration of expert 
opinions and reaching a consensus. Steps (3) and (4) are repeated until a consensus is reached.

For this study, an expert panel was formed consisting of six faculty members in a Faculty of Fine Arts, each having more than 10 years of experience in evaluating artworks for entrance exams. To form an initial list of evaluation criteria, individual interviews were conducted with the expert panel members to capture the verbal descriptions of sought-after criteria in these exams. At the end of these interviews, each participants' verbal descriptions were combined, resulting in a total of nine criteria as the initial list of evaluation criteria for entrance exams. To form an agreed-upon criteria list, four rounds of the Delphi process were administered. In the final stage, five criteria have culminated as an appropriate list. These criteria can be described as follows:

- Composition: refers to the organization and arrangement of drawn objects/figures within the borders of drawing space.

- Proportions and visual hierarchy: correct sizes of objects/figures (or their parts) about other objects (or other parts) in a composition.

- Unity (Wholeness): a sense of balance and harmony in a composition completing a whole; including the completion of the work.

- Emphasis: Dominant parts or pieces in a drawing composition used to create a focal point or hierarchy.

- Stroke quality: technical perfection of strokes reflecting skill, grace, ease, and confidence in drawing.

\section{Methods}

In this section brief definitions of fuzzy numbers and linguistic variables are given.

\subsection{Triangular Fuzzy Numbers}

A fuzzy number is a generalization of a typical, real number as it does not represent one single value yet rather a co-partnered set of conceivable qualities, where each conceivable quality has its particular specific weight between 0 and 1 , and the weight is known as the membership function (Yavuz, Pilli, and Pasham, 2014). The fuzzy membership function, known as the fuzzy set theory, has been introduced by Zadeh (1965) as an extension of the classical notion of set theory for problems that do not involve sharply defined criteria (Sun, 2010).

A triangular fuzzy number's membership function can be described (Chang, 1996: 650) as;

$$
\mu_{A}(X)=\left\{\begin{array}{cc}
\frac{x}{m-l}-\frac{l}{m-l}, & l \leq x \leq m \\
\frac{x}{m-u}-\frac{u}{m-u}, & m \leq x \leq u \\
0, & \text { otherwise }
\end{array}\right.
$$

where, $l \leq m \leq u$,

$l$ and $u$ stand for the lower and upper bound of $A$ respectively and $m$ for the mid or modal value of $A$. According to the structure of TFNs, the main operational laws for two triangular fuzzy numbers $A=\left(l_{1}, m_{1}, u_{1}\right)$ and $B=$ $\left(l_{2}, m_{2}, u_{2}\right)$ are as follows (Chang, 1996: 650):

Addition of two triangular fuzzy numbers $(\oplus)$

$A \oplus B \quad=\left(l_{1}, m_{1}, u_{1}\right) \oplus\left(l_{2}, m_{2}, u_{2}\right)=\left(l_{1}+l_{2}, m_{1}+m_{2}, u_{1}+u_{2}\right)$

Multiplication of two triangular fuzzy numbers $(\otimes)$

$A \otimes B=\left(l_{1}, m_{1}, u_{1}\right) \otimes\left(l_{2}, m_{2}, u_{2}\right)=\left(l_{1} l_{2}, m_{1} m_{2}, u_{1} u_{2}\right)$

Multiplication of any real number $\lambda$

$\lambda \otimes A=(\lambda, \lambda, \lambda) \otimes\left(l_{1}, m_{1}, u_{1}\right)=\left(\lambda l_{1}, \lambda m_{1}, \lambda u_{1}\right), \lambda>0, \quad \lambda \in R$

Reciprocal of a fuzzy number

$A^{-1}=\left(1 / u_{1}, 1 / m_{1}, 1 / l_{1}\right), u_{1}, m_{1}, l_{1}>0$

\subsection{Determination of Linguistic Variables}

A linguistic variable is "a variable whose values are words or sentences in a natural or artificial language" (Zadeh, 1975). Each linguistic variable can be assigned one or more linguistic values, which are connected to a numeric value through a membership function as explained above. In the literature, five-point to the nine-point scale of fuzzy linguistic terms are used to express unquantified matters. For this study, five fuzzy linguistic terms by triangular fuzzy numbers are adopted to express the importance weights of criteria and the rating of alternatives. Tables 1 and 2 explain the numerical values of the membership functions.

Table 1. Linguistic scale for importance

\begin{tabular}{lc}
\hline $\begin{array}{l}\text { Linguistic variable for importance } \\
\text { weights of criteria }\end{array}$ & $\begin{array}{c}\text { Triangular fuzzy number } \\
\text { (TFN) }\end{array}$ \\
\hline Equally important & $(1,1,1)$ \\
Weakly important & $(1,3,5)$ \\
Essentially important & $(3,5,7)$ \\
Very strongly important & $(5,7,9)$ \\
Absolutely more important & $(7,9,9)$ \\
\hline
\end{tabular}


Table 2. Linguistic scale for ratings

\begin{tabular}{lc}
\hline Linguistic variable for the ratings & Triangular fuzzy number (TFN) \\
\hline Very Poor & $(1,1,3)$ \\
Poor & $(1,3,5)$ \\
Medium & $(3,5,7)$ \\
Good & $(5,7,9)$ \\
Very Good & $(7,9,9)$ \\
\hline
\end{tabular}

\subsection{The Proposed Method}

In this study, a modified version of fuzzy hierarchical TOPSIS by Wang et al. (2009) is proposed. In the fuzzy hierarchical TOPSIS method; aggregation of expert opinions takes place in two stages, first in the determination of criteria weights, and second, in the integration of expert evaluations of alternatives. Therefore, aggregation reduces multiple expert evaluations to a single opinion. In the proposed method, aggregation of expert evaluations is done only once; during the integration of expert evaluations of alternatives that reflect their individual criteria weights. Since each expert's final judgment on a drawing inseparably includes their emphasis on each criterion. Aggregating evaluations this way better captures the essence of the decision process in the real case. Another modification of the fuzzy hierarchical TOPSIS method is the inclusion of the closeness coefficient which was originally employed in Chen's (2000) method.

The algorithm for the proposed method based on Wang et.al. (2009) as follows:

Step 1: Form a committee of experts, and then use the Delphi method to identify the evaluation criteria.

Step 2: Choose the appropriate linguistic variables for the importance weight of the criteria and the linguistic ratings for alternatives.

Step 3: Establish a hierarchical structure of the decision making problem.

Step 4: Ask experts to use pair-wise comparisons to get the degree of importance for all criteria, and to evaluate all of the alternatives under each criterion using linguistic variables.

Step 5: Use the Lambda-Max method to calculate the fuzzy weight of each criterion given by experts.

The fuzzy weights of the hierarchy could be computed as described by Csutora and Buckley (2001):

Let $\alpha=1$ then, AHP is applied to calculate the weight matrix $w_{m}^{k}$.

$w_{m}^{k}=\left[w_{i m}^{k}\right], \quad i=1,2,3 \ldots \ldots . n$

Let $\alpha=0$ then, AHP is applied to calculate the weight matrices, $w_{l}^{k}$ and $w_{u}^{k}$

$w_{l}^{k}=\left[w_{i l}^{k}\right], \quad i=1,2,3 \ldots \ldots . n$

$w_{u}^{k}=\left[w_{i u}^{k}\right], \quad i=1,2,3 \ldots \ldots . n$
To ensure the fuzziness of weight, two constants, $C_{l}^{k}$ and $C_{u}^{k}$, are calculated as follows:

$$
\begin{array}{ll}
C_{l}^{k}=\min \left\{\frac{w_{i m}^{k}}{w_{i l}^{k}}\right. \text { where } & 1 \leq i \leq \mathrm{n}\} \\
C_{u}^{k}=\max \left\{\frac{w_{i m}^{k}}{w_{i u}^{k}}\right. \text { where } & 1 \leq i \leq \mathrm{n}\}
\end{array}
$$

The lower bound $\left(w_{l}^{k^{*}}\right)$ and the upper bound $\left(w_{u}^{k^{*}}\right)$ of the weight matrix are defined as

$$
\begin{aligned}
& w_{l}^{k^{*}}=\left[w_{i l}^{k^{*}}\right], w_{i l}^{k^{*}}=C_{l}^{k} w_{i l}^{k} \quad i=1,2,3 \ldots \ldots . n \\
& w_{u}^{k^{*}}=\left[w_{i u}^{k^{*}}\right], w_{i u}^{k^{*}}=C_{u}^{k} w_{i u}^{k} \quad i=1,2,3 \ldots \ldots . n
\end{aligned}
$$

Aggregating $w_{l}^{k^{*}}, w_{m}^{k^{*}}$ and $w_{u}^{k^{*}}$, the fuzzy weight for decision maker $\mathrm{k}$ can be acquired as follows:

$$
W_{i}^{k}=\left(w_{l}^{k^{*}}, w_{m}^{k^{*}}, w_{u}^{k^{*}}\right), \quad i=1,2,3 \ldots \ldots . n
$$

Step 6: Check the consistency of expert evaluation results. Use the Consistency Index (CI) (Saaty, 1995)

Consistency ratio can be approximated via $\lambda$ max as;

$$
\begin{aligned}
& C I=\frac{\lambda_{\max }-n}{n-1} \\
& C R=\frac{C I}{R C}
\end{aligned}
$$

According to Saaty (1995), consistency ratio of an evaluation matrix should not exceed 0.1 level.

Step 7: Establish a normalized fuzzy performance matrix.

$x_{i j}^{k}=\left(l_{i j}^{k}, m_{i j}^{k}, u_{i j}^{k}\right)$ is the fuzzy evaluation value of expert $k$ of each alternative $i$ for each criterion $j$, which can be used to obtain the positive fuzzy performance matrix?

$R^{k}=\left[r_{i j}^{k}\right]_{m \times n}$

Eq.(17) and (18) can be used to obtain a value $\left[r_{i j}^{k}\right]$ which is within $[0,1]$. B and $\mathrm{C}$ are the set of benefit criteria and cost criteria respectively, and 
$r_{i j}^{k}=\left(\frac{l_{i j}^{k}}{u_{j}^{*}}, \frac{m_{i j}^{k}}{u_{j}^{*}}, \frac{u_{i j}^{k}}{u_{j}^{*}}\right), j \in B ;$

$r_{i j}^{k}=\left(\frac{l_{j}^{-}}{u_{i j}^{k}}, \frac{l_{j}^{-}}{m_{i j}^{k}}, \frac{l_{j}^{-}}{l_{i j}^{k}}\right), j \in C$;

where $u_{j}^{*}=\max _{i} u_{i j}^{k}$ if $j \in B ; \quad l_{j}^{-}=\min _{i} l_{i j}^{k}$ if $j \in C$

Step 8: Get the weighted normalized performance matrix.

$V^{k}=\left[v_{i j}^{k}\right]_{m x n} i=1,2 \ldots m \quad j=1,2 \ldots n$

where $v_{i j}^{k}=r_{i j}^{k} \otimes w_{j}^{k}$ and $v_{i j}^{k}, \forall i, j$ are normalized positive triangular fuzzy numbers and have values in the range $[0,1]$.

Step 9: Use the geometric average method to integrate all of the opinions of experts as follows:

$\widehat{V}_{i j}=\left(V^{1} \otimes V^{2} \otimes \ldots V^{k}\right)^{1 / k}$

Step 10: Determine FPIS and FNIS as follows:

For selecting $\widehat{V}_{i j}$ 's max and min, first rank the orderings of fuzzy number $\widehat{V}_{i j}$ by the metric distance method, then calculate FPIS and FNIS by Eq. (21) and (22).

FPIS: $A^{*}=\left\{\left(\max \widehat{V}_{i j} \mid j \in J^{*}\right),\left(\min \widehat{V}_{i j} \mid j \in J^{-}\right), i=1,2 \ldots m\right\}$

FPIS: $A^{-}=\left\{\left(\min \hat{V}_{i j} \mid j \in J^{*}\right),\left(\max \widehat{V}_{i j} \mid j \in J^{-}\right), i=1,2 \ldots m\right\} \quad$ (22)

where $\quad J^{*}=\{j=1,2 \ldots n \mid j \in B\}, \quad J^{-}=$ $\{j=1,2 \ldots n \mid j \in C\}$

also expressed as:

$$
\text { FPIS: } A^{*}=\left(\widehat{V}_{1}^{*}, \widehat{V}_{2}^{*} \ldots \widehat{V}_{n}^{*}\right)
$$$$
\text { FNIS: } A^{-}=\left(\widehat{V}_{1}^{-}, \widehat{V}_{2}^{-} \ldots \widehat{V}_{n}^{-}\right)
$$

Step 11: Calculate the distance between each point and FPIS and FNIS by the metric distance method. Using pnorm metric method, when $\mathrm{p}=1$, metric distance between the two fuzzy evaluation value can be calculated by Eq. (23):

Let $\hat{A}(x)=\left(l_{1}, m_{1}, u_{1}\right), \quad \hat{B}(x)=\left(l_{2}, m_{2}, u_{2}\right), \quad$ and $D(\hat{A}, \hat{B})$ can be simplified as:

$D(\hat{A}, \hat{B})=\left|\left(l_{1}, m_{1}, u_{1}\right)-\left(l_{2}, m_{2}, u_{2}\right)+\frac{l_{2}-l_{1}}{2}+\frac{u_{2}-u_{1}}{2}\right|$

and FPIS and FNIS can be calculated by Eq. (24)

$h_{i j}^{*}=D\left(\hat{V}_{i j}, \hat{V}_{j}^{*}\right), h_{i j}^{-}=D\left(\hat{V}_{i j}, \hat{V}_{j}^{-}\right)$
Step 12: Apply the Euclidean distance method to aggregate metric distance of FPIS to all criteria for every alternative, and similarly for FNIS as follows:

$$
S_{i}^{*}=\left[\sum_{j=1}^{n}\left(h_{i j}^{*}\right)^{2}\right]^{1 / 2}, i=1,2 \ldots m
$$

$S_{i}^{-}=\left[\sum_{j=1}^{n}\left(h_{i j}^{-}\right)^{2}\right]^{1 / 2}, i=1,2 \ldots m$

Step 13: Determine the rank order of all alternatives using Eq. (27).

When $S_{i}^{*}$ is smaller, meaning that $A_{i}$ is closer to the best $A^{*}$. Similarly when $S_{i}^{-}$is bigger, meaning $A_{i}$ is farther to the worst $A^{-}$. Closer to the best and farther to the worst will give a measure to rank the alternatives. The closeness coefficient of each alternative provides this measure and calculated as:

$C C_{i}=\frac{S_{i}^{-}}{S_{i}^{*}+S_{i}^{-}}, \quad i=1,2 \ldots m$

\section{Application}

In this section, the decision-making problem for the selection of art students among several competing candidates through an exam where the performances are evaluated by a committee is explained. Then, the steps of the proposed algorithm are presented. The evaluation committee is composed of six faculty members from the Faculty of Fine Arts in a Turkish university. The committee evaluated 20 drawings of the candidates who entered the first stage of the art exam based on the five evaluation criteria that were previously determined by its members. These criteria are as follows: composition; proportion and visual hierarchy; unity; emphasis; and stroke quality. The hierarchical structure of the decisionmaking process is shown in Figure 1. These six committee members respectively compare the five criteria and evaluate the twenty drawings using the linguistic values provided in Table 1 and Table 2. Following the proposed algorithm, the procedure for ranking the drawings is as follows:

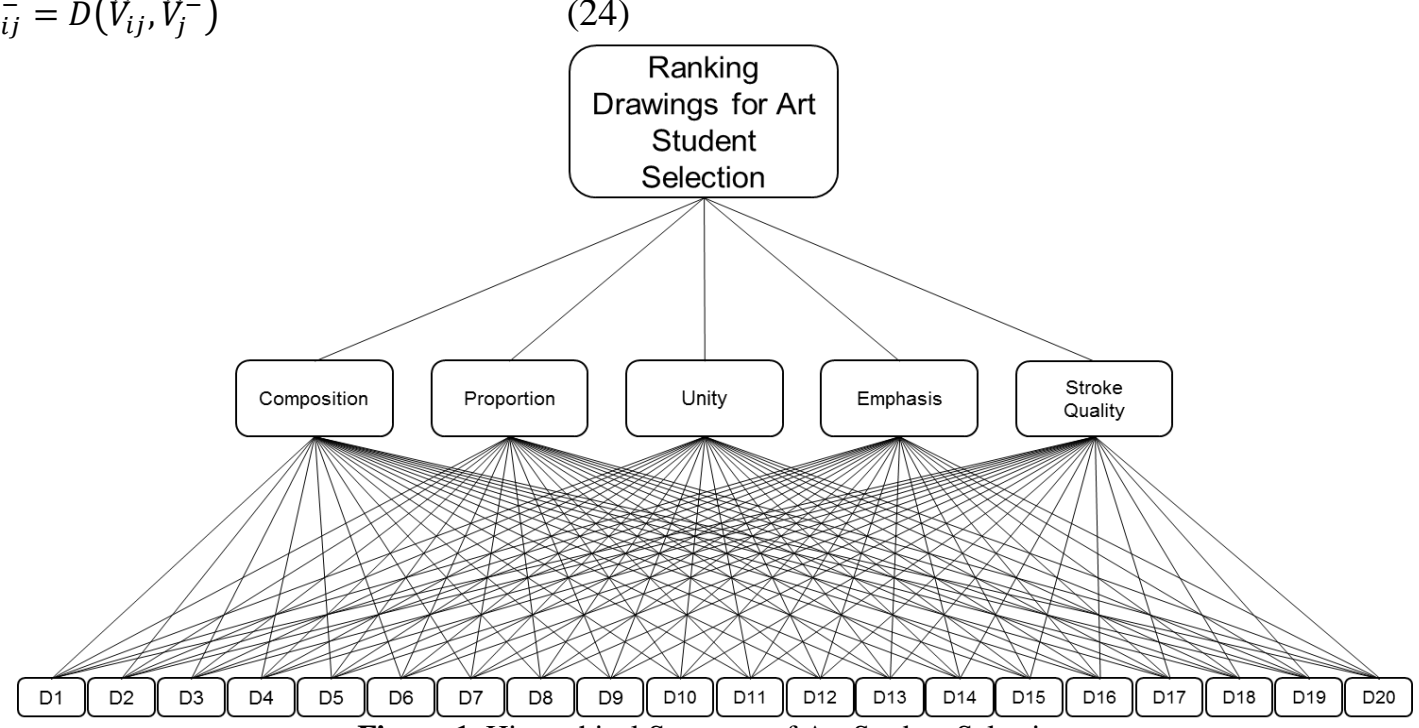

Figure 1. Hierarchical Structure of Art Student Selection 
From step 4 of the proposed algorithm committee Table 4 shows one of the committee member's evaluation members are asked to compare the five criteria and evaluate results. For the clarity of the presentation, only one of the the twenty drawings according to the five criteria. Table 3 and committee member's results is given.

Table 3. Comparison matrix

\begin{tabular}{lccccc}
\hline Committee Member 1 & Composition & Proportion & Unity & Emphasis & Stroke Quality \\
\hline Composition & $(1,1,1)$ & $(0.111,0.143,0.200)$ & $(1,1,1)$ & $(1,1,1)$ & $(0.111,0.143,0.200)$ \\
Proportion & $(5,7,9)$ & $(1,1,1)$ & $(5,7,9)$ & $(5,7,9)$ & $(1,1,1)$ \\
Unity & $(1,1,1)$ & $(0.111,0.143,0.200)$ & $(1,1,1)$ & $(1,1,1)$ & $(0.111,0.143,0.200)$ \\
Emphasis & $(1,1,1)$ & $(0.111,0.143,0.200)$ & $(1,1,1)$ & $(1,1,1)$ & $(0.143,0.200,0.333)$ \\
Stroke Quality & $(5,7,9)$ & $(1,1,1)$ & $(5,7,9)$ & $(3,5,7)$ & $(1,1,1)$ \\
\hline
\end{tabular}

$$
\mathrm{CI}=0.003
$$

\section{Table 4. Assessment grades given by committee member 1}

\begin{tabular}{cccccc}
\hline $\begin{array}{c}\text { Committee } \\
\text { Member 1 }\end{array}$ & Composition & Proportion & Unity & Emphasis & Stroke Quality \\
\hline D1 & VP & P & M & M & VP \\
D2 & M & G & G & G & G \\
D3 & G & P & G & G & G \\
D4 & VG & G & G & G & G \\
D5 & VG & VG & VG & VG & VG \\
D6 & G & G & P & G & G \\
D7 & G & M & G & G & M \\
D8 & P & VP & P & M & M \\
D9 & G & G & VG & VG & VG \\
D10 & VG & VG & VG & VG & VG \\
D11 & M & P & G & VG & G \\
D12 & G & P & VG & G & VG \\
D13 & M & VP & P & M & P \\
D14 & VG & VG & VG & VG & VG \\
D15 & VG & M & VG & VG & G \\
D16 & M & P & G & M & VP \\
D17 & VG & G & VG & G & VG \\
D18 & P & G & G & G & P \\
D19 & VG & VG & VG & VG & VG \\
D20 & G & G & G & G & G \\
\hline
\end{tabular}

From Table 3 and step 5 fuzzy weight value of the criteria was obtained. Table 5 shows the weight of the criteria of the same committee member.

Table 5. Criteria weights

\begin{tabular}{lc}
\hline Committee Member 1 & W \\
\hline Composition & $(0.060,0.060,0.060)$ \\
Proportion & $(0.368,0.421,0.421)$ \\
Unity & $(0.060,0.060,0.060)$ \\
Emphasis & $(0.062,0.065,0.070)$ \\
Stroke Quality & $(0.335,0.394,0.400)$ \\
\hline
\end{tabular}

Using Table 4 and step 7, normalized fuzzy performance results were calculated. Table 6 lists the results. 
Table 6. Normalized fuzzy performance matrix

\begin{tabular}{|c|c|c|c|c|c|}
\hline & Composition & Proportion & Unity & Emphasis & Stroke Quality \\
\hline D1 & $(0.111,0.111,0.333)$ & $(0.111,0.333,0.556)$ & $(0.333,0.556,0.778)$ & $(0.333,0.556,0.778)$ & $(0.111,0.111,0.333)$ \\
\hline D2 & $(0.333,0.556,0.778)$ & $(0.556,0.778,1.000)$ & $(0.556,0.778,1.000)$ & $(0.556,0.778,1.000)$ & $(0.556,0.778,1.000)$ \\
\hline D3 & $(0.556,0.778,1.000)$ & $(0.111,0.333,0.556)$ & $(0.556,0.778,1.000)$ & $(0.556,0.778,1.000)$ & $(0.556,0.778,1.000)$ \\
\hline D4 & $(0.778,1.000,1.000)$ & $(0.556,0.778,1.000)$ & $(0.556,0.778,1.000)$ & $(0.556,0.778,1.000)$ & $(0.556,0.778,1.000)$ \\
\hline D5 & $(0.778,1.000,1.000)$ & $(0.778,1.000,1.000)$ & $(0.778,1.000,1.000)$ & $(0.778,1.000,1.000)$ & $(0.778,1.000,1.000)$ \\
\hline D6 & $(0.556,0.778,1.000)$ & $(0.556,0.778,1.000)$ & $(0.111,0.333,0.556)$ & $(0.556,0.778,1.000)$ & $(0.556,0.778,1.000)$ \\
\hline D7 & $(0.556,0.778,1.000)$ & $(0.333,0.556,0.778)$ & $(0.556,0.778,1.000)$ & $(0.556,0.778,1.000)$ & $(0.333,0.556,0.778)$ \\
\hline D8 & $(0.111,0.333,0.556)$ & $(0.111,0.111,0.333)$ & $(0.111,0.333,0.556)$ & $(0.333,0.556,0.778)$ & $(0.333,0.556,0.778)$ \\
\hline D9 & $(0.556,0.778,1.000)$ & $(0.556,0.778,1.000)$ & $(0.778,1.000,1.000)$ & $(0.778,1.000,1.000)$ & $(0.778,1.000,1.000)$ \\
\hline D10 & $(0.778,1.000,1.000)$ & $(0.778,1.000,1.000)$ & $(0.778,1.000,1.000)$ & $(0.778,1.000,1.000)$ & $(0.778,1.000,1.000)$ \\
\hline D11 & $(0.333,0.556,0.778)$ & $(0.111,0.333,0.556)$ & $(0.556,0.778,1.000)$ & $(0.778,1.000,1.000)$ & $(0.556,0.778,1.000)$ \\
\hline D12 & $(0.556,0.778,1.000)$ & $(0.111,0.333,0.556)$ & $(0.778,1.000,1.000)$ & $(0.556,0.778,1.000)$ & $(0.778,1.000,1.000)$ \\
\hline D13 & $(0.333,0.556,0.778)$ & $(0.111,0.111,0.333)$ & $(0.111,0.333,0.556)$ & $(0.333,0.556,0.778)$ & $(0.111,0.333,0.556)$ \\
\hline D14 & $(0.778,1.000,1.000)$ & $(0.778,1.000,1.000)$ & $(0.778,1.000,1.000)$ & $(0.778,1.000,1.000)$ & $(0.778,1.000,1.000)$ \\
\hline D15 & $(0.778,1.000,1.000)$ & $(0.333,0.556,0.778)$ & $(0.778,1.000,1.000)$ & $(0.778,1.000,1.000)$ & $(0.556,0.778,1.000)$ \\
\hline D16 & $(0.333,0.556,0.778)$ & $(0.111,0.333,0.556)$ & $(0.556,0.778,1.000)$ & $(0.333,0.556,0.778)$ & $(0.111,0.111,0.333)$ \\
\hline D17 & $(0.778,1.000,1.000)$ & $(0.556,0.778,1.000)$ & $(0.778,1.000,1.000)$ & $(0.556,0.778,1.000)$ & $(0.778,1.000,1.000)$ \\
\hline D18 & $(0.111,0.333,0.556)$ & $(0.556,0.778,1.000)$ & $(0.556,0.778,1.000)$ & $(0.556,0.778,1.000)$ & $(0.111,0.333,0.556)$ \\
\hline D19 & $(0.778,1.000,1.000)$ & $(0.778,1.000,1.000)$ & $(0.778,1.000,1.000)$ & $(0.778,1.000,1.000)$ & $(0.778,1.000,1.000)$ \\
\hline D20 & $(0.556,0.778,1.000)$ & $(0.556,0.778,1.000)$ & $(0.556,0.778,1.000)$ & $(0.556,0.778,1.000)$ & $(0.556,0.778,1.000)$ \\
\hline
\end{tabular}

From step 8 and using Table 5 and Table 6 weighted normalized fuzzy performance matrix was computed as shown in Table 7.

Table 7. Weighted normalized fuzzy performance matrix

\begin{tabular}{|c|c|c|c|c|c|}
\hline & Composition & Proportion & Unity & Emphasis & Stroke Quality \\
\hline D1 & $(0.007,0.007,0.020)$ & $(0.041,0.140,0.234)$ & $(0.020,0.033,0.047)$ & $(0.021,0.036,0.055)$ & $(0.037,0.044,0.133)$ \\
\hline D2 & $(0.020,0.033,0.047)$ & $(0.204,0.327,0.421)$ & $(0.033,0.047,0.060)$ & $(0.035,0.050,0.070)$ & $(0.186,0.307,0.400)$ \\
\hline D3 & $(0.033,0.047,0.060)$ & $(0.041,0.140,0.234)$ & $(0.033,0.047,0.060)$ & $(0.035,0.050,0.070)$ & $(0.186,0.307,0.400)$ \\
\hline D4 & $(0.047,0.060,0.060)$ & $(0.204,0.327,0.421)$ & $(0.033,0.047,0.060)$ & $(0.035,0.050,0.070)$ & $(0.186,0.307,0.400)$ \\
\hline D5 & $(0.047,0.060,0.060)$ & $(0.286,0.421,0.421)$ & $(0.047,0.060,0.060)$ & $(0.049,0.065,0.070)$ & $(0.261,0.394,0.400)$ \\
\hline D6 & $(0.033,0.047,0.060)$ & $(0.204,0.327,0.421)$ & $(0.007,0.020,0.033)$ & $(0.035,0.050,0.070)$ & $(0.186,0.307,0.400)$ \\
\hline D7 & $(0.033,0.047,0.060)$ & $(0.123,0.234,0.327)$ & $(0.033,0.047,0.060)$ & $(0.035,0.050,0.070)$ & $(0.112,0.219,0.311)$ \\
\hline D8 & $(0.007,0.020,0.033)$ & $(0.041,0.047,0.140)$ & $(0.007,0.020,0.033)$ & $(0.021,0.036,0.055)$ & $(0.112,0.219,0.311)$ \\
\hline D9 & $(0.033,0.047,0.060)$ & $(0.204,0.327,0.421)$ & $(0.047,0.060,0.060)$ & $(0.049,0.065,0.070)$ & $(0.261,0.394,0.400)$ \\
\hline D10 & $(0.047,0.060,0.060)$ & $(0.286,0.421,0.421)$ & $(0.047,0.060,0.060)$ & $(0.049,0.065,0.070)$ & $(0.261,0.394,0.400)$ \\
\hline D11 & $(0.020,0.033,0.047)$ & $(0.041,0.140,0.234)$ & $(0.033,0.047,0.060)$ & $(0.049,0.065,0.070)$ & $(0.186,0.307,0.400)$ \\
\hline D12 & $(0.033,0.047,0.060)$ & $(0.041,0.140,0.234)$ & $(0.047,0.060,0.060)$ & $(0.035,0.050,0.070)$ & $(0.261,0.394,0.400)$ \\
\hline D13 & $(0.020,0.033,0.047)$ & $(0.041,0.047,0.140)$ & $(0.007,0.020,0.033)$ & $(0.021,0.036,0.055)$ & $(0.037,0.131,0.222)$ \\
\hline D14 & $(0.047,0.060,0.060)$ & $(0.286,0.421,0.421)$ & $(0.047,0.060,0.060)$ & $(0.049,0.065,0.070)$ & $(0.261,0.394,0.400)$ \\
\hline D15 & $(0.047,0.060,0.060)$ & $(0.123,0.234,0.327)$ & $(0.047,0.060,0.060)$ & $(0.049,0.065,0.070)$ & $(0.186,0.307,0.400)$ \\
\hline D16 & $(0.020,0.033,0.047)$ & $(0.041,0.140,0.234)$ & $(0.033,0.047,0.060)$ & $(0.021,0.036,0.055)$ & $(0.037,0.044,0.133)$ \\
\hline D17 & $(0.047,0.060,0.060)$ & $(0.204,0.327,0.421)$ & $(0.047,0.060,0.060)$ & $(0.035,0.050,0.070)$ & $(0.261,0.394,0.400)$ \\
\hline D18 & $(0.007,0.020,0.033)$ & $(0.204,0.327,0.421)$ & $(0.033,0.047,0.060)$ & $(0.035,0.050,0.070)$ & $(0.037,0.131,0.222)$ \\
\hline D19 & $(0.047,0.060,0.060)$ & $(0.286,0.421,0.421)$ & $(0.047,0.060,0.060)$ & $(0.049,0.065,0.070)$ & $(0.261,0.394,0.400)$ \\
\hline D20 & $(0.033,0.047,0.060)$ & $(0.204,0.327,0.421)$ & $(0.033,0.047,0.060)$ & $(0.035,0.050,0.070)$ & $(0.186,0.307,0.400)$ \\
\hline
\end{tabular}


At this stage all committee members' weighted normalized fuzzy performance results were aggregated using geometric average method. The results are shown in Table 8 .

\section{Table 8. Aggregated fuzzy performance matrix}

\begin{tabular}{|c|c|c|c|c|c|}
\hline & Composition & Proportion & Unity & Emphasis & Stroke Quality \\
\hline D1 & $(0.015,0.040,0.074)$ & $(0.018,0.043,0.084)$ & $(0.027,0.073,0.122)$ & $(0.020,0.055,0.098)$ & $(0.022,0.059,0.126)$ \\
\hline D2 & $(0.041,0.078,0.112)$ & $(0.051,0.076,0.124)$ & $(0.055,0.106,0.157)$ & $(0.037,0.075,0.121)$ & $(0.050,0.106,0.180)$ \\
\hline D3 & $(0.045,0.083,0.116)$ & $(0.025,0.061,0.102)$ & $(0.050,0.103,0.155)$ & $(0.034,0.073,0.119)$ & $(0.045,0.103,0.177)$ \\
\hline D4 & $(0.052,0.091,0.121)$ & $(0.052,0.089,0.131)$ & $(0.072,0.122,0.173)$ & $(0.031,0.069,0.114)$ & $(0.059,0.119,0.195)$ \\
\hline D5 & $(0.073,0.111,0.140)$ & $(0.065,0.104,0.142)$ & $(0.083,0.135,0.181)$ & $(0.061,0.100,0.145)$ & $(0.069,0.127,0.198)$ \\
\hline D6 & $(0.045,0.083,0.116)$ & $(0.040,0.077,0.119)$ & $(0.022,0.056,0.106)$ & $(0.022,0.040,0.086)$ & $(0.035,0.089,0.161)$ \\
\hline D7 & $(0.064,0.101,0.134)$ & $(0.040,0.077,0.119)$ & $(0.076,0.127,0.173)$ & $(0.058,0.096,0.145)$ & $(0.065,0.122,0.198)$ \\
\hline D8 & $(0.018,0.044,0.079)$ & $(0.015,0.023,0.061)$ & $(0.019,0.052,0.100)$ & $(0.016,0.050,0.092)$ & $(0.022,0.059,0.126)$ \\
\hline D9 & $(0.085,0.123,0.146)$ & $(0.065,0.104,0.142)$ & $(0.101,0.155,0.189)$ & $(0.081,0.122,0.157)$ & $(0.103,0.166,0.234)$ \\
\hline D10 & $(0.090,0.128,0.146)$ & $(0.075,0.114,0.148)$ & $(0.090,0.143,0.189)$ & $(0.061,0.100,0.145)$ & $(0.075,0.135,0.207)$ \\
\hline D11 & $(0.045,0.081,0.113)$ & $(0.026,0.064,0.106)$ & $(0.061,0.109,0.159)$ & $(0.047,0.087,0.131)$ & $(0.042,0.097,0.170)$ \\
\hline D12 & $(0.029,0.066,0.100)$ & $(0.018,0.054,0.095)$ & $(0.031,0.081,0.127)$ & $(0.023,0.061,0.106)$ & $(0.040,0.099,0.168)$ \\
\hline D13 & $(0.022,0.048,0.083)$ & $(0.015,0.029,0.069)$ & $(0.019,0.052,0.100)$ & $(0.016,0.035,0.078)$ & $(0.018,0.045,0.110)$ \\
\hline D14 & $(0.085,0.123,0.146)$ & $(0.083,0.124,0.155)$ & $(0.110,0.164,0.197)$ & $(0.086,0.127,0.157)$ & $(0.094,0.157,0.225)$ \\
\hline D15 & $(0.065,0.104,0.134)$ & $(0.034,0.076,0.122)$ & $(0.049,0.102,0.149)$ & $(0.051,0.092,0.137)$ & $(0.064,0.125,0.204)$ \\
\hline D16 & $(0.027,0.054,0.092)$ & $(0.017,0.045,0.090)$ & $(0.025,0.074,0.126)$ & $(0.022,0.058,0.102)$ & $(0.022,0.049,0.116)$ \\
\hline D17 & $(0.041,0.069,0.105)$ & $(0.031,0.074,0.120)$ & $(0.046,0.100,0.149)$ & $(0.041,0.079,0.126)$ & $(0.040,0.082,0.154)$ \\
\hline D18 & $(0.019,0.055,0.089)$ & $(0.045,0.087,0.135)$ & $(0.069,0.120,0.173)$ & $(0.041,0.079,0.126)$ & $(0.045,0.103,0.177)$ \\
\hline D19 & $(0.070,0.110,0.140)$ & $(0.068,0.111,0.155)$ & $(0.094,0.149,0.197)$ & $(0.067,0.106,0.151)$ & $(0.089,0.151,0.225)$ \\
\hline D20 & $(0.072,0.111,0.146)$ & $(0.059,0.103,0.155)$ & $(0.078,0.137,0.197)$ & $(0.056,0.104,0.157)$ & $(0.093,0.157,0.234)$ \\
\hline
\end{tabular}

From step 10 and using Table 8 FPIS and FNIS were FNIS was calculated. Using the Euclidean distance method, all calculated. Results are listed in Table 9. From step 11 using criteria values were aggregated. Then using Eq. (27) closeness Eq. (23) the distance between the entire criterion and FPIS and coefficient of each drawing was calculated.

Table 9. FPIS and FNIS

\begin{tabular}{cccccc}
\hline & Composition & Proportion & Unity & Emphasis & Stroke Quality \\
\hline FPIS & $(0.090,0.128,0.146)$ & $(0.083,0.124,0.155)$ & $(0.110,0.164,0.197)$ & $(0.086,0.127,0.157)$ & $(0.103,0.166,0.234)$ \\
FNIS & $(0.015,0.040,0.074)$ & $(0.015,0.023,0.061)$ & $(0.019,0.052,0.100)$ & $(0.016,0.035,0.078)$ & $(0.018,0.045,0.110)$ \\
\hline
\end{tabular}

Finally, all drawings were ranked according to the closeness coefficient score. Results are listed in Table 10.

Table 10. Ranking of the Drawings

\begin{tabular}{cccccccccc}
\hline Drawings & $\mathbf{S}^{+}$ & $\mathbf{S}^{-}$ & $\mathbf{C C}$ & Rank & Drawings & $\mathbf{S}^{+}$ & $\mathbf{S}^{-}$ & $\mathbf{C C}$ & Rank \\
\hline D1 & 0.368 & 0.063 & 0.147 & 18 & D11 & 0.228 & 0.199 & 0.466 & 12 \\
D2 & 0.218 & 0.208 & 0.488 & 11 & D12 & 0.297 & 0.132 & 0.308 & 16 \\
D3 & 0.240 & 0.186 & 0.437 & 13 & D13 & 0.414 & 0.018 & 0.042 & 20 \\
D4 & 0.182 & 0.251 & 0.579 & 9 & D14 & 0.020 & 0.412 & 0.955 & 1 \\
D5 & 0.110 & 0.318 & 0.743 & 6 & D15 & 0.182 & 0.253 & 0.582 & 8 \\
D6 & 0.314 & 0.147 & 0.318 & 15 & D16 & 0.360 & 0.072 & 0.167 & 17 \\
D7 & 0.152 & 0.276 & 0.646 & 7 & D17 & 0.256 & 0.173 & 0.403 & 14 \\
D8 & 0.400 & 0.034 & 0.078 & 19 & D18 & 0.225 & 0.220 & 0.495 & 10 \\
D9 & 0.041 & 0.396 & 0.906 & 2 & D19 & 0.062 & 0.365 & 0.856 & 3 \\
D10 & 0.084 & 0.353 & 0.807 & 5 & D20 & 0.072 & 0.358 & 0.833 & 4 \\
\hline
\end{tabular}


The final ranking of the drawings helps decisionmakers select a pre-determined number of students for admission to the program. The most important motivation to use MCDM models, as illustrated in this study, is to ease the complexity and workload of the decision-making process. Therefore, not only do the MCDM models correctly depict the real decision-making process but also decision-makers are satisfied and trust the models' results. Usually, in studies where the MCDM method is applied, the satisfaction of decision-makers from the results of the MCDM models are not questioned. This may not be an important issue for decisionmaking problems involving objective criteria. However, in situations where subjectivity and fuzziness play an important part in the decision-making process, decision-makers' perception of the models' results needs to be investigated. Moreover, since the proposed evaluation method for artworks is an unfamiliar approach to the experts in the field, it has been important for the study to capture the reactions of the decisionmakers.

To assess the validity and performance of the proposed MCDM model, a questionnaire asking to evaluate the place of the ranking of the given drawings in Table 10 is administered to the six committee members. In this questionnaire; according to their judgment, members are asked 7 point Likert-type questions to reveal the extent they agree with the final rank of each drawing.

Table 11. Ranking questionnaire results

\begin{tabular}{cccrcccr}
\hline Drawings & $\mathbf{N}$ & Median & \% Agree & Drawings & $\mathbf{N}$ & Median & \% Agree \\
\hline D1 & 6 & 6.0 & $100 \%$ & D11 & 6 & 4.5 & $50 \%$ \\
D2 & 6 & 5.5 & $83 \%$ & D12 & 6 & 6.0 & $100 \%$ \\
D3 & 6 & 5.0 & $67 \%$ & D13 & 6 & 4.0 & $50 \%$ \\
D4 & 6 & 6.0 & $83 \%$ & D14 & 6 & 5.0 & $67 \%$ \\
D5 & 6 & 5.5 & $67 \%$ & D15 & 6 & 5.5 & $67 \%$ \\
D6 & 6 & 4.0 & $50 \%$ & D16 & 6 & 6.0 & $83 \%$ \\
D7 & 6 & 5.0 & $67 \%$ & D17 & 6 & 7.0 & $100 \%$ \\
D8 & 6 & 5.0 & $67 \%$ & D18 & 6 & 6.0 & $100 \%$ \\
D9 & 6 & 6.0 & $83 \%$ & D19 & 6 & 6.5 & $100 \%$ \\
D10 & 6 & 5.0 & $67 \%$ & D20 & 6 & 7.0 & $100 \%$ \\
\hline
\end{tabular}

The median value of the six committee members' evaluation results shows that the ranking of the seventeen drawings is confirmed (Table 11). For drawings six, eleven, and thirteen; the committee members are undecided. Besides the drawings' ranking evaluations, the last part of the questionnaire questions the overall satisfaction from the results. All six committee members indicate that they are quite satisfied.

\section{Comparison of the Results}

To assess the performance of the proposed approach, Chen's method (2000) and fuzzy hierarchical TOPSIS method (Wang, Cheng, and Huang, 2009) are compared. Table 12 shows the comparison of the proposed method results with results from the latter two methods. As expected, the proposed method and fuzzy hierarchical TOPSIS results are very close to each other, since the proposed method is the modified version of fuzzy hierarchical TOPSIS. However, there are minor differences in the rankings each method produces. Since a result's calculation is based on how much it is closer to the best score and how farther to the worst score; the closeness of the calculated scores to the best and worst could be considered an indicator for comparison of the methods. The closeness between the calculated value and FPIS and FNIS is smaller in

the proposed method. Therefore, the proposed method is in accord with the conception of TOPSIS. The other two methods' scores are further apart from FPIS and FNIS as Chen's method shows poor performance compared to the other methods.

Another comparison can be made in terms of the dispersion of the scores as an indication of the discrimination power of the methods between alternatives. When the scores used for ranking are too close to each other, the discrimination power of the method reduces and there would be a great possibility that a small change in evaluation leads to a change in the overall ranking of the items. This could be an important shortcoming when judgments involve fuzziness. Therefore, the robustness of a fuzzy MCDM method can only be achieved if the sensitivity of the results is low to small changes in the judgments. The range of $\mathrm{CC}$ scores in the comparison of the three methods can be used as a measure. According to the results, the range of the scores is 0.065 for Chen's method, 0.789 for fuzzy hierarchical TOPSIS, and 0.913 for the proposed method. Based on these scores, it can be concluded that Chen's method performs poorly in discriminating between alternatives since the spread of closeness coefficient scores is very close to each other. 
Table 12. Comparison of three methods' results

\begin{tabular}{ccccccccccccc}
\hline & \multicolumn{4}{c}{ Proposed Method } & \multicolumn{4}{c}{ Fuzzy hierarchical TOPSIS } & \multicolumn{4}{c}{ Chen's method } \\
\hline Drawings & $\mathrm{S}^{+}$ & $\mathrm{S}^{-}$ & $\mathrm{CC}$ & Rank & $\mathrm{S}^{+}$ & $\mathrm{S}^{-}$ & $\mathrm{CC}$ & Rank & $\mathrm{S}^{+}$ & $\mathrm{S}^{-}$ & $\mathrm{CC}$ & Rank \\
D1 & 0.368 & 0.063 & 0.147 & 18 & 0.273 & 0.081 & 0.229 & 15 & 4.123 & 0.353 & 0.079 & 15 \\
D2 & 0.218 & 0.208 & 0.488 & 11 & 0.215 & 0.131 & 0.379 & 12 & 4.068 & 0.410 & 0.092 & 12 \\
D3 & 0.240 & 0.186 & 0.437 & $\mathbf{1 3}$ & 0.221 & 0.124 & 0.359 & $\mathbf{1 3}$ & 4.073 & 0.403 & 0.090 & $\mathbf{1 3}$ \\
D4 & 0.182 & 0.251 & 0.579 & $\mathbf{9}$ & 0.179 & 0.172 & 0.491 & $\mathbf{9}$ & 4.031 & 0.452 & 0.101 & $\mathbf{9}$ \\
D5 & 0.110 & 0.318 & 0.743 & 6 & 0.107 & 0.241 & 0.692 & 5 & 3.956 & 0.520 & 0.116 & 5 \\
D6 & 0.314 & 0.147 & 0.318 & 15 & 0.291 & 0.074 & 0.203 & 17 & 4.135 & 0.345 & 0.077 & 17 \\
D7 & 0.152 & 0.276 & 0.646 & $\mathbf{7}$ & 0.146 & 0.204 & 0.582 & $\mathbf{7}$ & 3.999 & 0.481 & 0.107 & $\mathbf{7}$ \\
D8 & 0.400 & 0.034 & 0.078 & 19 & 0.291 & 0.072 & 0.198 & 18 & 4.145 & 0.337 & 0.075 & 19 \\
D9 & 0.041 & 0.396 & 0.906 & $\mathbf{2}$ & 0.033 & 0.321 & 0.907 & $\mathbf{2}$ & 3.883 & 0.600 & 0.134 & $\mathbf{2}$ \\
D10 & 0.084 & 0.353 & 0.807 & 5 & 0.083 & 0.276 & 0.769 & 4 & 3.922 & 0.555 & 0.124 & 3 \\
D11 & 0.228 & 0.199 & 0.466 & 12 & 0.197 & 0.159 & 0.446 & 10 & 4.041 & 0.434 & 0.097 & 10 \\
D12 & 0.297 & 0.132 & 0.308 & 16 & 0.283 & 0.068 & 0.195 & 19 & 4.135 & 0.344 & 0.077 & 18 \\
D13 & 0.414 & 0.018 & 0.042 & 20 & 0.281 & 0.075 & 0.210 & 16 & 4.136 & 0.349 & 0.078 & 16 \\
D14 & 0.020 & 0.412 & 0.955 & $\mathbf{1}$ & 0.020 & 0.332 & 0.944 & $\mathbf{1} *$ & 3.868 & 0.611 & 0.136 & $\mathbf{1}^{*}$ \\
D15 & 0.182 & 0.253 & 0.582 & $\mathbf{8}$ & 0.171 & 0.182 & 0.516 & $\mathbf{8}$ & 4.019 & 0.459 & 0.102 & $\mathbf{8}$ \\
D16 & 0.360 & 0.072 & 0.167 & 17 & 0.312 & 0.057 & 0.155 & 20 & 4.154 & 0.319 & 0.071 & $20^{-}$ \\
D17 & 0.256 & 0.173 & 0.403 & $\mathbf{1 4}$ & 0.265 & 0.091 & 0.256 & $\mathbf{1 4}$ & 4.115 & 0.361 & 0.081 & $\mathbf{1 4}$ \\
D18 & 0.225 & 0.220 & 0.495 & 10 & 0.218 & 0.137 & 0.385 & 11 & 4.071 & 0.410 & 0.092 & 11 \\
D19 & 0.062 & 0.365 & 0.856 & 3 & 0.078 & 0.270 & 0.776 & 3 & 3.934 & 0.549 & 0.122 & 4 \\
D20 & 0.072 & 0.358 & 0.833 & 4 & 0.136 & 0.226 & 0.624 & 6 & 3.983 & 0.503 & 0.112 & 6 \\
\hline
\end{tabular}

\section{Discussion}

This study can be considered as the first attempt to explore the applicability of MCDM methods to art-related decision making. Evaluating artworks requires implicit expertise that to some degree involves subjective/perceptive judgment. In this study, capturing and identifying experts' decision criteria is a crucial stage in fully understanding the decision making process in artwork evaluation. This stage help experts understand and accept the proposed MCDM model since they are not used to working with mathematical models. For this purpose, individual interviews are conducted with experts to create a list of criteria. Then, the Delphi technique is used to identify and build consensus among the experts for evaluations of the drawings. For the MCDM model, a modified version of the fuzzy hierarchical TOPSIS method is proposed and applied to a part of the student placement procedure to an undergraduate art program. In the proposed method, contrary to the general aggregation procedures of multiple decisionmaking evaluations, aggregation is used only at the final stage to create a single decision. Although this approach may cause individual decision results to be farther apart from each other in cases where there are big disagreements among decisionmakers; it suits much better for decision-making problems when both the criteria and alternative evaluations are hard to differentiate and the case involves perceptive subjectivity and fuzziness. When compared with similar methods, the proposed model performs better in terms of closeness of the scores to the best and worst and in addition to the dispersion of the scores and discrimination between each evaluated item. Based on these findings, the proposed method can be preferred in decision problems when subjectivity/perceptivity plays an important role in implicit evaluation decisions as it does in the art-related cases.

Since subjectivity plays an important role in decision making in these types of decision-making problems, measuring the acceptance of the method's results by the decision-making group is important and should be an integral part of the analysis. In this study, the proposed model's results are assessed by the participating experts, and the method is justified as an acceptable method for evaluation. A questionnaire is employed for this purpose. However, further studies on how to effectively measure the satisfaction levels of decision-makers in different cases would be beneficial. They can be an important contribution to decision analysis methods in measuring and incorporating the satisfaction levels of decision-makers to the results of preferred MCDM methods.

\section{Acknowledgment}

The author would like to thank the faculty members in the Faculty of Fine Arts at Mustafa Kemal University for their contributions in his understanding of the evaluation of art 


\section{(C) Center for Promoting Education and Research (CPER) USA}

www.cpernet.org

drawings and their participation in this study. Special members in understanding their terminology and standpoint appreciation goes to Prof. Dr. Seval Yavuz for her valuable during the criteria development stage of the study. insights and being a bridge between the author and the faculty

\section{References}

Bernstein, B. (2000). Pedagogy, symbolic control, and identity. Revised Edition. Oxford, New York: Rowman and Littlefield Publishers, Inc.

Bolton, H. (2006). "Pedagogy, subjectivity and mapping judgement in art, a weakly structured field of knowledge". Journal of Education, 40, 59-78.

Büyüközkan, G., Feyzioğlu, O., \& Nebol, E. (2007). "Selection of the strategic alliance partner in logistics value chain". International Journal of Production Economics, 113(1), 148-158.

Chang, D.-Y. (1996). “Applications of the extent analysis method on fuzzy AHP”. European Journal of Operational Research, 95(3), 649-655.

Chang, Y.-H., \& Yeh, C.-H. (2002). “A survey analysis of service quality for domestic airlines”. European Journal of Operational Research, 139(1), 166-177.

Chen-Tung Chen. (2000). "Extensions of the TOPSIS for group decision-making under fuzzy environment". Fuzzy Sets and Systems, (114), 1-9.

Csutora, R., \& Buckley, J. J. (2001). "Fuzzy hierarchical analysis: the Lambda-Max method". Fuzzy Sets and System, (120), $181-195$.

Gumus, A. T. (2009). "Evaluation of hazardous waste transportation firms by using a two-step fuzzy-AHP and TOPSIS methodology". Expert Systems with Applications, 36(2), 4067-4074.

Hekkert, P. (2006). "Design aesthetics: principles of pleasure in design". Psychology Science, 48(2), 157-172.

Hwang, C.L., \& Yoon, K. (1981). Multiple Attribute Decision Making: Methods and Application, New York: Springer.

Kahraman, C., Çevik, S., Ates, N. Y., \& Gülbay, M. (2007). "Fuzzy multi-criteria evaluation of industrial robotic systems". Computers \& Industrial Engineering, 52(4), 414-433.

Kleindorfer, P. R., Kunreuther, H. G., \& Schoemaker, P. J. H. (1993). Decision Sciences: An Integrative Perspective. Cambridge: Cambridge University Press.

Leder, H., Belke, B., Oeberst, A., \& Augustin, D. (2004). "A model of aesthetic appreciation and aesthetic judgments". British Journal of Psychology, 95, 489-508.

Liang, G.-S. (1999). "Fuzzy MCDM based on ideal and anti-ideal concepts". European Journal of Operational Research, 112(3), 682-691.

Lin, M.-C., Wang, C.-C., Chen, M.-S., \& Chang, C.-A. (2008). "Using AHP and TOPSIS approaches in customer-driven product design process". Computers in Industry, 59(1), 17-31.

Linstone, H. A., \& Turoff, M. (Eds.). (1975). The Delphi method: Techniques and applications. Boston, MA: Addison-Wesley.

Nodine, C. F., Locher, P. J., \& Krupinski, E. A. (1993). “The Role of Formal Art Training on Perception and Aesthetic Judgment of Art Compositions". Leonardo, 26(3), 219-227.

Saaty, T.L. (1980), The Analytic Hierarchy Process, New York: McGraw-Hill International.

Saaty, T.L. (1995). Decision Making for Leaders: The Analytic Hierarchy Process for Decisions in a Complex World. Pittsburgh, PA: RWS Publications.

Seçme, N. Y., Bayrakdaroğlu, A., \& Kahraman, C. (2009). "Fuzzy performance evaluation in Turkish Banking Sector using Analytic Hierarchy Process and TOPSIS". Expert Systems with Applications, 36(9), 11699-11709.

Sun, C.-C. (2010). "A performance evaluation model by integrating fuzzy AHP and fuzzy TOPSIS methods". Expert Systems with Applications, 37(12), 7745-7754.

Volker, L. (2011). Deciding about Design Quality: Value judgements and decision making in the selection of architects by public clients under European tendering regulations. Leiden, NLD: Sidestone Press.

Wang, J.-W., Cheng, C.-H., \& Huang, K.-C. (2009). "Fuzzy hierarchical TOPSIS for supplier selection”. Applied Soft Computing, 9(1), 377-386.

Wang, Y.-J., \& Lee, H.-S. (2007). “Generalizing TOPSIS for fuzzy multiple-criteria group decision-making”. Computers \& Mathematics with Applications, 53(11), 1762-1772. 
Yavuz, V. A., Pilli, R., \& Pasham, P. R. (2014). "A fuzzy analytic hierarchy process model for the evaluation of print advertisement designs". (pp. 635-651). 15th International Symposium on Econometrics, Operations Research and Statistics Proceedings Book, Isparta, Turkey.

Zadeh, L.- A. (1965). "Fuzzy sets". Information and Control, 8(2), 338-353.

Zadeh, L. A. (1975). "The concept of a linguistic variable and its application to approximate reasoning-I". Information Sciences, 8(3), 199-249. 